\title{
Organizational Learning in Nigerian Institutions: Constraints and Challenges
}

\author{
Michael D. Oisamoje, $(\mathrm{PhD})^{1}$, Enaruna Ehimwenma Idubor ${ }^{2},(\mathrm{PhD})$ \\ ${ }^{I}$ (Department of Business Administration, Benson Idahosa University, Benin City, Nigeria) \\ ${ }^{2}$ (Edo State Judiciary, Benin City, Edo State, Nigeria)
}

\begin{abstract}
Organisations are recognised as legal and corporate entities. They have an image, and they can sue and be sued. To that extent therefore, this paper posits that organizations can also learn, and asserts that the absence or dearth of adequate organisational learning culture denies organizations the much needed competitive edge necessary to survive and remain viable in the contemporary and highly globalised world. The paper x-rays the technical and social perspectives of organisational learning and argues that the learning process is context and culture-driven. Conceding that effective organisational learning practice enhances performance, it highlights some hindrances to the learning process, suggests remedies and concludes with a case study of the organisational learning problems of a Nigerian public sector organization.
\end{abstract}

Keywords - Corporate organisations, globalised world, learning culture, organizational learning

\section{Introduction}

The importance of learning cannot be over-emphasized whether it is on individual or organizational level. Learning has become a veritable tool for growth, adaptation and capacity building in the complex and fast changing environment of the $21^{\text {st }}$ century. It is believed that the operational viability of corporate institutions is correlated with the organisation's level of compliance with organizational learning norms and procedures. It is thus imperative that to develop an effective organizational learning culture, an institution has to shift from defensive reasoning and action (a reactive strategy) to offensive and strategic reasoning (or a proactive strategy). If any organization is to become relevant in its industry, then it should model a clear line of organizational learning action and implementation.

Organizational learning theory is about how learning takes place in organizations, the structures that are put in place to ensure that the learning is effective and sustained, the factors that can hinder organizational learning and what can be done to tackle those challenges. Organizations consist of individuals and it is these individuals who perform the actions that produce organizational learning [1]. However, there are conditions precedents that the organization itself must create to enable the learning by the individuals within the organization to be successful, and to be transmittable to the organization.

Learning is synonymous with growth and this is usually not an easy process. It requires commitment to both time and resources to enable it yield the desired results.

History is replete with organizations that ignored learning and are today non-existent or at best back benchers in the industries they once ruled. In summing up the importance of organizational learning, it is alleged that "the rate at which individuals and organizations learn may become the only sustainable competitive advantage especially in knowledge intensive industries" [2].

\section{Concept of Organizational Learning}

It is argued that there is no such thing as organizational learning except when speaking metaphorically but that all learning is individual learning. Learning takes place inside the heads of people and an organization can only learn by learning from its members or others who possess such knowledge that the organization desires [3]

Every organization consists of individuals who make decisions and those who implement these decisions on behalf of the organization. These individuals must all be involved in the learning if the process of organizational learning is to be successful. It can be said therefore that the learning of individuals within the organization cannot be separated from organizational learning. [1] supports this view when he posits that organizations do not perform the actions that produce the learning, rather it is the individual members of the organization who behave in ways that lead to it. However, organizations can create conditions that facilitate such learning. The way in which organizational learning takes place is therefore affected by the context and culture of the organization.

The concept of organizational learning has become very important especially in the last decade or so because it has now been recognized as a powerful tool for the improvement of the performance of the organization. This is even more glaring when the fact that uncertainty is a dominant factor in the existence of 
organizations is taken into consideration. Organizational learning is concerned with the development of new knowledge or insights that have the potential to influence behaviour [4]. Organizational learning refers broadly to an organization's acquisition of understanding, know - how, techniques and practices of any kind and by any means [5]. Organizational learning has been defined as a process of coordinated systems change, with mechanisms built-in for individuals and groups to access, build and use organizational memory, structure and culture to develop long term organizational capacity [6].

Organizational learning is executed on the basis of rules. It is not done arbitrarily, but is guided by the organization's laid down rules in respect of what and how to learn. The experience that has been hitherto acquired within the organization will shape the content of these rules. Organizational learning takes deliberate thought and planning if it is to prove worthwhile. It should result in behaviour change and this is not an easy process because it may require changes in the structure, processes and how individuals within the organization work unless the people who make up the organization can learn and adapt accordingly, organizational learning will be an exercise in futility. However, it is note worthy that organizational learning may not always be beneficial [3]. According to them, organizations can learn the wrong thing; for example manufacturing something that nobody wants.

Organisational learning is a process and is thus time-dependent. While [7] confirms that organizational performance is directly linked to the rate of learning, [8] recommends that the rate of learning within the organization should be equal to or greater than the rate of change in the environment if the organization is not to be consumed by the effects of change.

\subsection{Perspectives of Organisational Learning}

Organizational learning has been viewed from two basic perspectives - as a technical process and as social process. It is stated that the technical view assumes organizational learning to be the effective processing, interpretation and response to information both inside and outside the organization [9]. This information may or may not be quantitative, but it is generally explicit and in the public domain. The social perspective on the other hand focuses on the way people make sense of their experiences at work. These experiences may be derived from explicit or from tacit sources. For the purpose of clarification, explicit knowledge is the type that can be codified - recorded, held in data bases, and can be accessed, while tacit knowledge exists only in the minds of people, it is difficult to articulate in writing and is acquired through personal experience [11].

The social view holds that organizational learning emerges from social interactions, inherent normally in the natural work setting. While it derives from the process of making sense of data, the more tacit and "embodied" forms of learning on the other hand involve situated practices, observation and emulation of skilled practitioners and socialization enshrined in a community of practice. Those who view organizational learning from the social perspective also see it as a social construct, as a political process and/or as a cultural artifact.

\subsection{Importance of Organizational Learning}

The days when the resources of an organization were considered to be only physical and financial in nature are long gone. It is now apparent that all the physical, material and financial resources that an organization possesses are worthless without a proactive team in place to manage these resources. It is thus argued that organizations that fail to develop their human resources are doomed to fail. This point is buttressed by noting that organizational learning outcomes contribute to the development of a firm's resource-based capabilities [12]. Furthermore, since the knowledge and skills that workers possess generate productive capital, it is important for organizations to invest in their employees so that the much needed intellectual capital can be developed in order to enhance the organizations stock of skills and knowledge [13]. The knowledge and skills come from education and training and include the training that experience brings.

In organizational learning, it is not only important to pay attention to the explicit aspects of learning, but also to the more intricate and often hidden or unnoticed learning that takes place and influences what occurs within the organization. It is also estimated that about $10 \%$ of all learning takes place in formal training while some $20 \%$ of learning comes from materials and systems, existing processes, manuals, and embedded methodologies, among others. The remaining $70 \%$ of learning occurs "on the job" through people talking with their managers, vide interactions with peers, through finding experts and by making mistakes [14]. It is further noted that the "hidden learning" is acquired and developed in the normal course of work by people acting as individuals and in groups or "communities of practice" [15].

Organizational learning can not only be seen to have the twin impact of creating people who are more effective and result-oriented at accomplishing organizational goals, but also in creating an enabling environment for these people to achieve their goals. Some experts argue that organizational learning improves the organization's adaptability and efficiency during times of change [16]. This is because learning enables quicker and more effective responses to a complex and dynamic environment. Noting that organizational learning is a prerequisite for innovation, increased information sharing, communication, mentoring, understanding and the 
ultimate quality of organizational decisions, others believe that organizational learning increases organizational work flexibility and the opportunities for creativity [17].

\subsection{Process of Organizational Learning.}

It is posited that there is a three-stage process of organizational learning which consists of the following: knowledge acquisition, knowledge dissemination and shared implementation. These stages are briefly discussed.

- Knowledge Acquisition: For deliberate organizational learning to take place, the organization must acquire knowledge by monitoring the environment. It must then use information systems to store, manage and retrieve the information when needed. Knowledge acquisition also involves research and development, training and further education. Organizational learning can also be achieved by re-arranging existing knowledge, revising previous knowledge and the building and revision of theories.

- Information Dissemination: Acquiring knowledge through the means stated above, is not enough. For the knowledge to be beneficial to the organization, it must be properly disseminated to those who can put it to the best use. Explicit knowledge can easily be codified and made readily available to those in need of it, while tacit knowledge can be passed on through person to person interactions and other such means. Informal communication creates great opportunity for learning and innovation to take place. The information after been disseminated must be correctly interpreted by those who receive it. A common understanding or meaning must be attached to the disseminated information. There should be interaction between the information and its interpretation. This is because greater learning occurs when interpretations are fitted to information.

- Shared Information: This can also be referred to as organizational memory. A repository where knowledge is stored for future use must be created and this must be made readily available to those who need it. [1] suggests that organizational learning takes place under two situations. One, when an organization achieves its goals, and two, when a mismatch between goals and outcomes are identified and corrected. He makes a distinction between what he calls the single - loop, double - loop and triple - loop learning.

- Single-Loop Learning: The emphasis here is on improving the capacity of the organization to achieve known objectives by detection and correction of errors within a given set of governing variables which is linked to incremental change in the organization. Single - loop learning is associated with routine and behavioural learning. Here, the organization is learning without a significant change in its basic assumptions.

- Double-Loop Learning: This type of learning re - evaluates the nature of the organization's objectives, and the values and beliefs surrounding them. This re-evaluation comes about as a result of the organization been unable to succeed in achieving its set goals or even when it overshoots its expectations. Learning here goes to the fundamental objectives of the organization and it requires sometimes an almost total departure from the status quo. Double loop learning involves questioning the governing variables themselves and frequently involves radical changes such as the wholesale reversion of systems, and the alterations in strategy, among others. The organizational culture will need to change because of this type of learning. This is where the organization 'learns to learn'.

- Triple Loop Learning: While the single - loop learning is about accepting change without any fundamental change in basic assumptions and core beliefs, double and triple-loop learning are about 'the why' and 'the how' to change the organization even if it implies a change in the fundamental structure and strategy.

Triple-loop learning is about adaptability; remaining and maintaining an organization that is in a near continuous state of change in structure, strategy, and goals. This is even when the organization enjoys an apparent level of optimal adaptation. An important advantage of this type of learning is that the organization learns a variety of design features and remains flexible. This method of operation is extremely efficient and it is what is required for survival in a fast and unstable environment.

Some stakeholders insist that single-loop learning is appropriate for routine, repetitive issues as it helps to get the everyday job done. On the other hand, double and triple loop learning question why the problem arose in the first place. They tackle the root causes instead of simply addressing the surface symptoms, as is the case with single-loop learning [1]. The process of organizational learning is further described from a systems theory perspective, and it makes a very important distinction between adaptive and generative learning [18]. This perspective is synonymous with Argyris' proposal of single loop, and double loop learning [1].

- Adaptive Learning: It is noted that adaptive learning is only the first stage of organizational learning [18]. In adaptive learning, the organization adapts to changes in its environment. Adaptive learning comes along with a low degree of organizational change, it is a process of incremental changes and it is more automatic and less cognitively induced than generative learning. Where only adaptive learning is done, the basic assumptions, cultural values and organizational structure poses a difficult problem for the organization. Adaptive learning involves making changes in reaction to changing environmental conditions. 
- Generative Learning: The deficiency of adaptive learning and the problems organizations which adapt it alone encounter, is because they did not go beyond this stage. Adaptive learning is reactive while generative learning is proactive. In generative learning, changes are made on a more willful basis. Here, learning goes beyond reacting to environmental changes. Generative learning involves innovation and creativity. It goes beyond adapting to a change but anticipating the change before it occurs. This process of learning leads to a total reframing of an organization's experiences, with the organization learning from the process. This is a learning process that is invaluable to modern organizations that have to compete in a dynamic and unstable environment. In the absence of this competitive edge, the organization would, at best, be merely reactive. Such a posture could spell doom for the organization. Some experts indicate that generative learning is about creating; as it requires systemic thinking, shared vision, personal mastery, team learning and creative tension [18].

\section{Distinction between Organizational Learning and the Learning Organization}

Some authors do not make any distinction between organizational learning and the learning organizations. However, [19] states that the two terms are often assumed to be synonymous and that they are not. The term "learning organization" is used to denote a company that facilitates the learning of its members and continuously transforms itself [20]. It is an organization in which one cannot but learn because learning is so engrained into the fabric of life. It is a group of people who are continually enhancing their capacity to create what they want to create [18]. On the other hand, it is believed that organizational learning is concerned with the development of new knowledge or insights that have the potential to influence behavior [4]. It is also stated that organizational theory examines how in this context individual and team learning can be translated into an organizational resource [12]. This is thus the nexus with the processes of knowledge management.

A learning organization is an organization that deliberately constructs structures and strategiesp; 0 in order to enhance and maximize organizational learning [21]. Organizational learning is the activity and the process by which organizations eventually reach the ideal of a learning organization [22]. The concept of the learning organization is considered to be integrated with knowledge management initiatives so that different forms of knowledge can be linked [10]. Thus organizational learning can be used in adding value to goods and services. However, it is asserted that the learning organization movement has helped to emphasize the importance of knowledge management as a practical proposition for promoting organizational learning [12].

\subsection{Factors Influencing Organizational Learning.}

The process of organizational learning requires change which may sometimes be drastic in nature. Whether drastic or not, it is still a departure from the status quo into that will influence the success or otherwise of organizational learning. Thus, the factors that influence organizational learning are now examined here under.

- Structure: Organizational structure has been described as a firm's formal role configuration, procedures, governance, control mechanism, authority and decision making process. Structure is influenced by situational factors like organizational size and age. It reflects an management's determination of what a firm does and how it does it given its chosen strategies [23]. For organizational learning to be successful, the structure of the organization must be or become organic in nature. An organic structure creates a decentralized system. It encourages people to think for themselves and it accepts when errors are made. It is also open and more flexible in their approach to problem solving.

- Strategy: The strategy than an organization adopts will determine whether organizational learning will be fostered or not. Strategy and structure are closely linked. This is because strategic competitiveness can be attained when the firm's selected structure is congruent with its formulated strategy [24]. For strategy to be effective in creating organizational learning, the organization must position itself in such a way that allows for the effective implementation of the strategy. It is also observed that as firms evolve and change their strategies, new structural arrangements are required. Moreover existing structures influence the future selection of strategies [25]. Strategy formation and implementation must therefore interact continually to influence management's choice of strategy and structure.

- Culture: Organizational culture or corporate culture has been described as the patterns of values norms, beliefs, attitudes and assumptions that may not have been articulated but that shape the ways in which people behave and get things done [12]. Value refers to what is believed to be important about how people and organizations 'behave'. Different types of culture can be found in organizations. For example, the following four cultures have been identified: the power culture, the role culture, the achievement culture and the support culture [26].

Obviously, an organizational where the culture is supportive, where people contribute out of a sense of commitment and solidarity, and where relationships are characterized by mutuality and trust, will more positively impact on organizational learning than one that is power-oriented. Where the culture in an organization does not support organizational learning, such culture has to change if organizational learning 
is desirable. However, changing the culture of an organization is not an easy task and most times not every aspect of the culture has to, or can be, changed.

- Environment/Climate: The whole essence of organizational learning or creating a learning organization is to enable the firm develop the continuous capacity to adapt to the environment, predict and master it. There appears to be some confusion between the terms "organizational climate" and "organization culture". According to [27], culture refers to the deep structure of the organization which is rooted in values, beliefs and assumptions held by organizational members. In contrast, climate refers to those aspects of the environment that are consciously perceived by organizational members. Organizational climate can therefore be regarded as how people perceive or feel about the culture of the organization, which can make learning either easier or more difficult. The firm must perceive its culture objectively and accurately in order to align itself with the environment. This is in order to remain competitive and innovative, and this can only be done through learning.

- Technology: Modern organizations now make demands on their members to learn something new, to do what they have not done before, to use technology intelligently, purposefully, deliberately and responsibly [28]. This is the age of cutting edge technology and for organizational learning to be effective; it must make the most of technological tools available as these indeed make learning easier and more structured.

When technology is put to proper use, it can maintain and enhance existing skills. It creates flexibility, creates more interesting and challenging jobs, and it enhances speed and accuracy. It also increases and enhances information storage and processing. Information systems can impact positively on organizational learning by affecting contextual factors such as structure and environment. Aspects of technology include telecommuting, automation/robotics, artificial intelligence, biotechnology, internet, extranet, electronic multimedia communications, and computers, among others.

- Human Resources: Human resources factors that can influence organizational learning include: initiative, positive personality traits, commitment to professional development, and interest in the profession, as well as self efficacy and love of learning. These factors help in enhancing motivation for informal organizational learning [29].

An investigation of the manufacturing environment found that the approach to human resources management and quality orientation was significantly related to organizational learning [30]. This view is corroborated by the observation that management support and the involvement of consultants facilitate organizational learning and change [31].

It is also noted that motivation, enthusiasm, involvement, clarity and understanding of role, increased responsibility, perception as a strategic partner, a developed learning culture, management support, organizational re-structure, job redesign, investment in human resources and the learning environment make significant difference in organizational learning [23].

- Time Factors: The following factors have been identified as influencing organizational learning: time perspective, time pressure, simultaneity, synchronization, and windows of opportunity, learning cycles and life cycles and the history of the firm [32].

- Group Factors: The group factors are acknowledged to include planning, interaction, communication, negotiation skills, strategies, feedback, leadership, role-playing, brainstorming and motivation [33].

- Board of Directors: Organizational learning is an expensive, resource-intensive process. Sometimes ideologies, values, norms, goals structure and strategy have to drastically change. If the board of directors does not see the need for these changes to take place or if they feel that the price to be paid is too high, the entire process can be haphazardly done or jettisoned all together.

\subsection{Constraints of Organizational Learning in Nigeria.}

While many of the constraints facing organizational learning are not confined to Nigeria, there are however some constraints that are peculiar to Nigeria due to what has been identified as the 'Nigerian factor' [34]. Some of these issues are discussed below.

- An Unsupportive Organizational Structure: As earlier mentioned, for organizational learning to be effective, the structure and hence strategy of the organization must be supportive. For most organizations in Nigeria, the structure is mainly bureaucratic. While bureaucracy is not bad in itself, it poses a serious challenge for organizational learning. This is because although bureaucracy produces a high degree of predictability and reliability, it also reduces flexibility which is what is most needed in organizational learning. Secondly, the rules and procedures in a highly bureaucratic organization are highly formalized and applied to all types of situations whether appropriate or not. It therefore becomes a problem when a novel situation arises or conditions change and the same old rules are applied to them. Clearly, this just would not work. Bureaucracy also creates employees alienation as the high specialization required by this type of organizational structure reinforces the employee's feeling of not been relevant. This is because the activities are routine and can be learned and executed by others easily. 
Lastly, bureaucracy concentrates a great deal of power in the hands of a very few people and this can lead to frustration on the part of the majority. If these few powerful individuals are not open to the idea of change, then it just would not happen.

- Demands of Organizational learning: Learning and organizational learning require change, sacrifice and hard work. Where there are people in possession of power within the organization who benefit from the status quo, or who are unwilling to make the required effort, these people will definitely oppose organizational learning. This is the case in some Nigerian organizations, especially the civil service.

- Lack of time: This can also be an impediment to organizational learning as learning does not take place over night. Furthermore, the change resulting from learning is also not automatic. The gains of learning are usually not apparent in a short time, so patience is required to see the benefits of organizational learning. Nigerians generally appear to be in a hurry and are thus impatient. This maybe one of the reasons why developmental policies fail here so often. Secondly, there is lack of continuity. When a course of action is initiated by one management committee, the incoming management team more often than not discards it to initiate their own plan regardless of the value, quality and benefits of the plan of its predecessor and the ineptness of the new policy been implemented.

- Lack of adequate interaction with colleagues: This also negatively affects organizational learning in Nigerian organizations. There ought to be a forum for colleagues to interact, compare notes, seek advice from the more experienced ones, relay the difficulties they face at work and generally brainstorm on ways to learn new things and how to make learning easier. Unfortunately, this is a rare scenario in many Nigerian organizations. Where seminars and workshops are organized by organizations, especially government organizations, most of what is taught or information given is meaningless and unrelated to the day to day job that the employees are engaged in. Even when what is learnt is helpful, implementation, often takes a very long time, if it happens at all. There is a dearth of the idea of mentoring strategy which is supposed to be used to hone and enhance the skills and competencies of new employees.

- Lack of motivation: This is another problem facing the average Nigerian worker. Motivation can be provided by opportunities for promotion and other such things. If the organization is dynamic, the employee will be proud and excited to be a part of it and therefore be willing to work at accomplishing the organization's goals. Individual and group learning is the bedrock of organizational learning, so when individuals learn and their learning is not put to good use or recognized, then motivation for learning is diminished. Individuals within the organization should not only be given the support and opportunity to learn, they should also be given the chance to effect the changes that will make their learning beneficial to the organization.

- Lack of resources: This is a major constraint on organizational learning in Nigeria. This is because as earlier stated, organizational learning is an expensive process. The organization must not only be willing to undergo organizational learning, it must also be able to.

Other problems facing learning in Nigerian organizations include unclear work roles, extra work, lack of confidence, wrong perception of roles, insufficient learning culture, lack of innovation, lack of recognition for personal or group achievements, a bad reward system and a flawed recruitment process.

\section{Organizational Learning in Edo State Judiciary}

Having examined the problems associated with organizational learning in Nigerian organizations, it is now necessary to examine how lack of adequate organizational learning affects government institutions typified by the Edo State Judicairy. Government is the biggest employer of labour in Nigeria. In addition to the fact that Government organizations have been identified as over bloated and largely inefficient [35], it is thus not surprising that the country still suffers from a low level of development and industrialization.

This paper now discusses how the lack of adequate organizational learning has affected this organization.

The Edo State Judiciary consists of the High Court Directorate and the Customary Court of Appeal Directorate. The High Court Directorate includes all the high courts and magistrate courts, while the Customary Court of Appeal Directorate consists of the District Customary Courts, the Area Customary Courts and the Customary Court of Appeal. This section focuses on the Customary Court of Appeal Directorate.

There are eighteen Area Customary and twenty-eight District Courts in Edo State. While the Area Courts are presided over by a Lawyer called the "President" and assisted by two lay members in addition to other administrative staff, the district courts are presided over by non-professionals in conjunction with other staff. It is noteworthy that the Nigerian Court system is over a hundred years old. However, operationally, the procedures and methods adopted by the court system during the colonial era are still very much in force today [36]. This scenario has serious implications for organizational learning.

While it is true that as a Government establishment, the organization is large and therefore needs a rigid bureaucratic structure to be effective, those things that limit efficiency ought to be done away with to improve the overall efficiency of the organization. For instance, in the early 1920s during the colonial rule, there was what was known as district courts, which were presided over by the British and later by learned Nigerians. In 
those courts, the judges wrote long hand in court records and these records were kept in bookshelves or cupboards, which were susceptible to termite attacks and the vagrancies of the environment. Sadly, most of these important records have been lost forever due to improper archival storage. It is unbelievable that in the $21^{\text {st }}$ Century the same inadequate methods of information storage and retrieval are still been used. The advances in technology have not been put to use in the Edo State Judiciary. There are neither digital/electronic copies of these records, nor backup systems to ensure that these records can easily be accessed in case of a fire out break or even theft of these court records/books.

In this institution, the three-stage process of organizational learning earlier specified as knowledge acquisition, knowledge dissemination and shared implementation [37], is virtually none existent. Besides, there is little drive to acquire knowledge at the level of the organization. Even when there is a semblance of knowledge acquisition through seminars and workshops, the knowledge acquired is usually not relevant to the day-to-day skills required to perform effectively on the job. Furthermore, the content of the training is usually the same over the years, and new things are hardly learnt. Even when new knowledge is gained, there is this aura of secrecy that surrounds the office; with the custodian of the new knowledge having the tendency to jealously guard the knowledge acquired. For instance, situations abound where the deputy is oblivious of the workings of the office of his immediate boss. This type of behaviour negatively affects shared implementation.

The kind of learning that occurs in this organization is mainly single-loop learning. One of the principles of organizational learning is to re-evaluate and re-examine what had been hitherto taken for granted. In the Nigerian Civil Service, employees are not encouraged to think for themselves, initiative is rarely entertained. The rules are laid down, they are not to be questioned but rigidly adhered to whether understood or not, whether, effective or not.

The human resource of any organization is regarded as its most important resource. It is therefore expected that the Human Resource Manager (HRM) should be one that is quite experienced in managing personnel. Unfortunately, this is not the case in the Edo State Judiciary. Though there is a Personnel Department headed by a director, he has no special training in personnel management or credentials to enable him perform effectively in that office.

The Director of Personnel is usually the highest ranked Court Registrar in the Directorate. He automatically steps into the office of the Director of Personnel when the incumbent retires. This is irrespective of the fact that the work of a Court Registrar differs substantially from that of the head of Personnel. Secondly, the Chief Registrar of the Directorate is the head of administration. The Chief Registrar is appointed from the ranks of Area Court Presidents who sit and preside over both criminal and civil matters in court. The Chief Registrar is by training, a lawyer and may have functioned as a judge for many years before been appointed as the Chief Registrar to head administration. A key element of administration is Personnel management and the Chief Registrar oversees the office of the Director of Personnel. The Chief Registrar has right to overrule the recommendations of the Director of Personnel, who in any case has no authority to carry out any action without the permission of the Chief Registrar.

The overall picture here is unappealing for effective personnel management. The overall picture here is one in which there is a Director of Personnel who is not a trained Human Resource Manager (HRM), and a Chief Registrar who heads administration with the orientation of a judge. Naturally, the focus of the Chief Registrar while occupying that office would most likely not be that of managing personnel effectively but rather that of planning how to get appointed to the enviable position of a Judge of the Customary Court of Appeal.

There is need for career Human Resource Managers who understand both the need for, and the process of, organizational learning to be in charge of the human resources so that the organization can profit from the numerous benefits of organizational learning.

\section{Conclusion}

The gains of organizational learning cannot be overemphasized. Organizational learning cannot be separated from the learning of the individuals who make up the organization. Hence, organizations should create enabling environments to foster learning among the individuals in the organization. It is therefore imperative that organizations should have viable human resource management teams that understand the benefits of organizational learning and its processes. There are numerous organizational learning problems that confront Nigerian organizations. These problems can however be surmounted as long as there is commitment on the part of management to stick with the learning process no matter the cost or time required to realize the desirable results.

\section{Recommendations}

In view of the foregoing, it is hereby recommended that:

1 If Nigerian organizations are to develop the competitive edge required to survive in the highly dynamic and globalised economy, organizational learning becomes a sine quo non; 
2 Organisations should adopt organizational learning principles in order to be proactive and thus be able to cope with the ever-changing uncertain operating environments;

3 Every organisation's structure, strategy, culture, internal operating environment and applicable technology should be re-worked in such a way as to accommodate and encourage the inculcating of organizational learning;

4 Organizations should be ready and willing to invest the time and other resources necessary to foster an organizational learning environment; and

5 Government establishments in particular should re-evaluate their internal operations and procedures in order to do away with archaic processes and norms that discourage the growth and development of a viable organizational learning atmosphere.

\section{References}

[1]. C. Argyris, On Organizational Learning (Cambridge, MA: Blackwell Publishers Inc., 1992).

[2]. R. Stata, Organizational learning and continuous improvement, in E. A. Locke and V. K. Jain, (Eds.), The International Journal of Organizational Analysis. 3(1), 45-68.

[3]. E. A. Locke, and V. K. Jain,. Organizational learning and continuous improvement, The International Journal of Organizational Analysis. 3(1), 1995, 45-68.

[4]. C. Mabey, and G. Salaman, Strategic human resource management. (Oxford: Blackwell Publishing, 1995).

[5]. C. Argyris, and D. A. Schon, Organizational Learning II: Theory Method and Practice. (Reading, MA: Addison-Wesley, 1996)

[6]. G. K. Watkins, and V. J. Marsick, Building the learning organization: A new rule for human resource development. Studies in Continuing Education 14 (2), 1992, 115-129.

[7]. Utomi, P. Managing Uncertainty, Competition and Strategy in Emerging Economies. (LBS Management Series. Ibadan: Spectrum Books Ltd, 2003).

[8]. B. Garrat, Learning is the core of Organizational Survival: Action Learning is the key integrating process". Journal of Management Development 6(2), 1987, 38-44.

[9]. M. Easterby-Smith, L. Araujo, and J. Burgoyne, J. (Eds.), Organizational Learning and the Learning Organization, (London: Sage, 1987).

[10]. J. Burgoyne, Learning Organizations, in M. Amstrong, (Ed.) Handbook of Human Resources Management. Practice, 8th ed., (London:The Bath Press Ltd. ,1999).

[11]. L. Nonaka, and H. Takeuchi, The knowledge creating company. (New York: Oxford University Press, 1995).

[12]. M. Armstrong, A handbook of Human Resource Management Practice ( $9^{\text {t }}$ th ed. Kogan: Page Publishers, 2003 ).

[13]. R. G., Ehrenberg, and R. S. Smith, Modern Labour Economics, (New York: Harper-Collins, 1994).

[14]. J. Bersin, Building a learning culture, (2005), Retrieved from http://www.cednaeurope.org\newsletter.

[15]. E. Wenger, and W. M. Snyder, Communities of Practice: The Organizational Frontier. Harvard Business Review. Jan- Feb. 2000.

[16]. R. Garrat, Creating a Learning Organization. Institute of Directors, London, 1990.

[17]. R. O. Igbinomwanhia, and R. O. Agbaragu, The learning organization: A change-mastering paradigm, unpublished M.Sc thesis in the Department of Business Administration, University of Benin, 2007.

[18]. P. M. Senge, The fifth discipline: The art and practice of the learning organization, (New York: Doubleday, 1991).

[19]. R. Harrison, Employee Development, 2nd, ed., (London.: Institute of Personnel and Development, 1997).

[20]. M. Pedler, J. Burgogyne, and T. Boydell, The Learning Company: A strategy for sustainable development. 2nd, ed., (London: McGraw- Hill, 1997)

[21]. M. Dodgson, Organizational learning: A review of some literatures. Organizational studies, 14(3), 1993, 375-394.

[22]. M. Finger, and S. B. Brand, The concept of the learning organization applied to the information of the public sector, in M. EasterbSmith, L. Araujo and J. Burgoyne (Eds.) Organizational Learning and the Learning Organization, (London: Sage, 1999).

[23]. S. Sambrook, and J. Stewart, Factors influencing learning in European learning-oriented organizations: Issues for management, Journal of European Industrial Training , 24 (2-4), 2000, 209-213.

[24]. M. J. Marquardt, Building the learning organization, (New York: McGraw- Hill, 1996).

[25]. K.. Weick, Making sense of the organization, (Boston: Blackwell, 2000).

[26]. E. H. Schein, Organizational Culture and Leadership, (San Francisco: Jossey-Bass Publishers, 1985).

[27]. D. R Denison, What is the difference between Organizational Culture and Organizational Climate? A native's point of view on a decade of paradigm wars. Academy of management review 21(3), 1996, 619-654.

[28]. P. Drucker, The effective executive, (London:Heinemann, 1969).

[29]. M. C. Lohman, A survey of factors influencing the engagement of two professional groups in informal workplace learning activities, Human Resource Development Quarterly 16(4), 2005, 501-527.

[30]. H. Shipton, J. Dawson, M. West, and M. Patterson, Learning in manufacturing organizations: What factors predict effectiveness? Human Resource Development International 5(1), 2002, 55-72.

[31]. M. Albert, Managing Change: Creating a learning organization focused on quality problems and Perspectives in Management, 1, $2005,47-54$.

[32]. C. Weber,. and A. Berthoin Antal, The role of time in organizational learning, in M. Dierkers, A. Berthoin Antal, J. Child \& I. Nonaka (Eds.). Handbook of organizational learning and knowledge, (New York: Oxford University Press, 2003, 351-368).

[33]. D. McConnell, and J. Zhao, Exploration and analysis of factors influencing group leaning. Networked Learning conference, 2004, Retrieved from http://ww.shf.ac.uk/nic2004/proceedings/individual.papers/zhao.McConnell.htm

[34]. E. E. Omoregie, Evaluation of the Achievements and Failures of the first four national development plans, 1962-1985, . MBA thesis, University of Benin, Benin City, 1998.

[35]. L. S. Sanusi, Growth Prospects for the Nigerian Economy, 8th Convocation Lecture, Igbinedion University, Okada, 2010.

[36]. Nigerian Customary Court of Appeal, Retrieved from Nigerian www.nigeriancustomary_court_of_appea.org

[37]. M. Dale, (1994) Learning organizations, in M. Armstrong, A handbook of Human Resource Management Practice 9th ed, (Kogan: Page Publishers, 2003). 